\title{
From Fellowship to Stewardship? Explaining Extra-Role Behavior of Volunteer Firefighters
}

\author{
Lisa Schmidthuber ${ }^{1}$ (D) $\cdot$ Dennis Hilgers ${ }^{1}$ (B)
}

Published online: 20 September 2018

(C) The Author(s) 2018

\begin{abstract}
We present a research model of extra-role behavior, integrating the literature on public service motivation (PSM) with stewardship theory. We propose that the extent to which volunteers perform activities that go beyond role prescription depends on the individual's PSM. Our research model is further grounded in the notion that a stewardship-oriented organizational culture serves as a means to enhance the effect of PSM on extra-role behavior. We empirically test this research model in a sample of 475 Austrian and German volunteer firefighters and provide evidence that PSM positively relates to extra-role behavior at the $10 \%$ significance level. Furthermore, firefighters' commitment to the occupation and organization positively moderates the relationship between PSM and extra-role behavior. We also find that stewardship-like characteristics, such as a motivating work design and perceived organizational support, directly relate to extra-role behavior. Implications for research and practice are discussed, focusing on the relevance of these insights for volunteerism research and management.
\end{abstract}

Keywords Extra-role behavior · Volunteering · Firefighters · Emergency service - Public service motivation $\cdot$ Stewardship theory

Lisa Schmidthuber

lisa.schmidthuber@jku.at

Dennis Hilgers

dennis.hilgers@jku.at

1 Institute for Public and Nonprofit Management, Johannes Kepler University, Altenbergerstraße 69, 4040 Linz, Austria

\section{Introduction}

Emergency service workers such as firefighters make an enormous contribution to society's safety by protecting citizens in case of fire, environmental disaster, or other emergency issues. In many Western countries such as Germany and Austria, volunteer fire departments support professional, paid fire departments. Professional fire departments are located in cities in most cases, whereas volunteers usually ensure safety in the wide rural areas across the country. While career firefighters are compensated for their services, volunteer firefighters perform occasional fire suppression or other emergency services oncall 24/7 on an honor basis while pursuing some other form of income. In addition to responding to calls for help (e.g., quenching a fire), many on-call firefighters volunteer for other non-emergency duties at the fire service. They spend their time and effort, for example, training young people, raising funding, or maintaining the equipment. Although these activities go beyond simple role descriptions, they are crucial for the survival of the organization, drive organizational success, and improve organizational effectiveness. In line with Schaubroeck and Ganster (1991) and Somech and Drach-Zahavy (2000), these activities are characterized as extra-role behavior, defined as behavior that goes beyond specified role requirements and is geared toward fostering organizational goals.

Unfortunately, little is known about the conditions that promote the extra-role behaviors of volunteers in organizations. Although numerous studies have attempted to identify the personal characteristics of individuals that predict working extra hours (Organ 1988; George and Bettenhausen 1990; Somech and Drach-Zahavy 2000), little research has focused on the extra-role behavior of volunteers (Schaubroeck and Ganster 1991; Millette and 
Gagné 2008; Shantz et al. 2014; Brauchli et al. 2017; Cady et al. 2018). Consequently, this article examines the factors associated with volunteers' extra-role behavior and questions the conditions under which volunteer firefighters go above and beyond their emergency duties (e.g., responding to 911 calls) and conduct extra work in a sense of prosocial organizational behavior.

First, extra-role behavior is proposed to be associated with the public service motivation (PSM) of volunteers, as individuals motivated by concerns for the public interest are more likely to volunteer and perform prosocial behavior (Brewer and Selden 1998; Houston 2006). Second, this article aims to determine the PSM-extra-role behavior relationship by drawing on stewardship theory (Donaldson and Davis 1991; Davis et al. 1997). Stewardship theory explains individuals' behavior based on individual motivation and provides a contrasting perspective to agency theory (Jensen and Meckling 1976). This theory assumes that individuals' behavior is driven by the interest of the organization (Davis et al. 1997), which contradicts the model of man proposed by agency theory. Whereas "agents" are economically motivated to complete tasks, "stewards" have noneconomic motivation that makes them pursue pro-organizational behavior. This paper thus suggests that extra-role behavior is shaped by the degree to which fire departments adopt a stewardship perspective. The multi-faceted nature of a stewardship-oriented culture is captured by five characteristics (i.e., intrinsic motivation, job characteristics, commitment, organizational identification, and perceived organizational support). The link between PSM, stewardship-oriented culture, and extra-role behavior is empirically tested by quantitative data analysis using survey data collected from 475 Austrian and German volunteer firefighters.

This study contributes to the literature in multiple ways. First, it extends previous works on volunteer behaviors (e.g., van Schie et al. 2015; Mayr 2017; Henderson and Sowa 2018) by focusing on individuals who volunteer as firefighters in disaster and emergency service. It empirically examines the effect of PSM on the extra-role behavior of volunteer firefighters by arguing that altruistic beliefs relate to behavior oriented toward favoring society. Consequently, we propose that individuals with high PSM are more willing to work beyond the call of duty than those with low altruistic beliefs. We thus extend recent research that has suggested that individual beliefs and attitudes can significantly influence volunteer performance (e.g., Ertas 2014).

Second, this work contributes to research on PSM by questioning whether and how PSM relates to observable behavior (Bozeman and $\mathrm{Su} 2015$ ) and testing the effect of PSM on volunteers' extra-role behavior. Whereas past research has focused on the antecedents of PSM, scholars now aim to shed light on the outcomes of PSM on individual behavior (Campbell and Im 2016; Van Loon et al. 2017; Shim and Faerman 2017; Kim 2018; Leisink et al. 2018). We aim to contribute to this literature.

Third, this study applies the ideas of stewardship theory in the context of volunteer emergency service and investigates how a stewardship-oriented culture might be related to extra-role behavior. Stewardship theory, in contrast to agency theory (Jensen and Meckling 1976), is more appropriate and useful to explain employees' motivation, relationships, and behaviors in a not-for-profit organization (Kluvers and Tippett 2011).

The remainder of this study is structured as follows. In second section, extra-role behavior is defined, and previous research is outlined. Thereafter, the stewardship perceptive is introduced, and hypotheses are formulated. Third section outlines the research setting. Fourth section describes the data collection and measures. Fifth section presents the results of multivariate analysis and discusses the findings. Final section outlines the implications of this research, provides directions for further research and concluding remarks.

\section{Theory and Hypotheses}

\section{Extra-Role Behavior}

Different forms of extra-role behavior are distinguished in the literature, such as organizational citizenship behavior (Organ 1988), prosocial behavior (George and Bettenhausen 1990), spontaneous behavior (George and Brief 1992), and contextual behavior (Borman and Motowidlo 1993). Extra-role behavior can be defined as "behavior that is not a formal or informal aspect of the worker's role but which in the aggregate promotes the organization's goals" (Schaubroeck and Ganster 1991, 569). Somech and DrachZahavy $(2000,650)$ refer to extra-role behavior as "those behaviors that go beyond specified role requirements, and are directed towards the individual, the group, or the organization as a unit, in order to promote organizational goals." Accordingly, extra-role behaviors must be voluntary, not part of the role description or formally required, and not formally rewarded or penalized if they are not performed (Van Dyne and LePine 1998; Somech and Drach-Zahavy 2000). Finally, extra-role behavior must be advantageous for the organization (e.g., Turnipseed and Rassuli 2005).

This study defines extra-role behavior as those behaviors performed by individuals that go beyond specified role requirements and directly or indirectly benefit organizational goals and society, whereas in-role behavior is characterized by tasks in accordance with formally described 
roles. Extra-role behavior performed by firefighters can be seen as a specific type of extra-role work because it benefits both the organization by fulfilling organizational objectives and society at large.

Extra-role behaviors are shown to benefit organizational effectiveness and success (e.g., Podsakoff et al. 1997). Furthermore, employees who demonstrate extra-role behavior are less likely to leave the organization (George and Bettenhausen 1990). Previous research has found various antecedents of extra-role behavior, such as job satisfaction (Organ 1988), organizational commitment (MacKenzie et al. 1998), perceived fairness (Moorman et al. 1993), self-efficacy (Somech and Drach-Zahavy 2000), collective efficacy (Somech and Drach-Zahavy 2000), intrinsic and extrinsic job cognition (Williams and Anderson 1991), group cohesiveness and socialization experiences (George and Bettenhausen 1990).

\section{Public Service Motivation and Extra-Role Behavior}

The literature on PSM, defined as "an individual's predisposition to respond to motives grounded primarily or uniquely in public institutions and organizations" (Perry and Wise 1990, 368), assumes that individuals who provide a public service have special motives for work engagement compared to those working in the private sector (Frederickson and Hart 1985; Perry and Porter 1982; Ritz et al. 2016). PSM helps to explain motivation and behavior in the public realm and is characterized by individuals' intention of doing good for others and fostering the well-being of society (Perry and Hondeghem 2008). Individuals with high levels of PSM have a strong desire to help people and service society at large (Perry and Wise 1990; Rainey and Steinbauer 1999).

PSM is not used only to explain why public employees have a greater focus on serving the public interest than those working in the private sector (Rainey and Steinbauer 1999). Scholars have applied the construct to capture the work motivation of private sector employees (Moulton and Feeney 2011), nonprofit employees (Taylor 2010), and volunteers (Coursey et al. 2008) and thus consider PSM a "behavioral predisposition of any individual, irrespective of whether or where he or she is employed rather than a characteristic specific to the public sector" (Esteve et al. 2016, 178). In addition to exploring the antecedents of PSM (e.g., Moynihan and Pandey 2007), scholars call for research on the behavioral implications of PSM to test whether individuals with high levels of PSM are more prone to act in favor of communities and societies (Brewer 2008; Bozeman and $\mathrm{Su} 2015$ ).

Although empirical research on the consequences of PSM on behavior is scarce (Ritz 2009), previous research provides the first results of the effect of PSM on observable behavior. These studies focus on behavioral outcomes either outside or inside the organization. First, in explaining individual involvement in charitable activities, Houston (2006) showed that government and nonprofit employees are more likely to volunteer than for-profit workers and explain this difference in prosocial behavior based on PSM. Using a sample of undergraduates, Clerkin et al. (2009) found a positive effect of PSM on volunteering and donating. Esteve et al. (2016) tested the effect of PSM on prosocial behavior and found that the relationship is even stronger when the prosocial behavior of other group members is high. Recently, Leisink et al. (2018) found that public interest commitment had a positive effect on volunteering activities among Dutch public and semi-public employees.

Second, studies have focused on the influence of PSM on organizational behavior and performance. Kim (2006) studied the organizational citizenship behavior of Korean civil servants and found a positive effect of PSM on altruism and generalized compliance. Ritz (2009) related the PSM of the Swiss federal administration to internal efficiency in terms of cost reduction, process simplification, and decision making. Findings from Pandey et al. (2008) indicated a positive and significant effect of PSM on an individual's helping behavior directed at co-workers. Shim and Faerman (2017) and Kim (2018) investigated PSM in the Korean public sector and found a positive link between PSM and organizational citizenship behavior and PSM and knowledge sharing behavior.

In summary, individuals with high levels of PSM are highly concerned with serving the public interest. PSM is linked to prosocial behavior because the desire to serve the public interest is expected to relate to behavior oriented toward favoring society. Initial empirical research on the behavioral implications of PSM provides support for the notion that PSM is related to volunteering for society at large and to prosocial organizational behavior. This study thus argues that the individual predisposition to act in favor of society positively relates to extra-role behavior.

Hypothesis 1 PSM is positively associated with extrarole behavior.

\section{Stewardship Theory}

Stewardship theory, a theory derived from psychology and sociology, explains human behavior based on individual motivation and offers a contrasting perspective to agency theory (Davis et al. 1997). Agency theory (Jensen and Meckling 1976) assumes that individuals are rational beings who seek to maximize their individual utility. When principals (e.g., stakeholders, stockholders) charge agents (e.g., firms) with managing the principals' wealth, financial 
incentives or monitoring instruments are used to govern principal-agency relationships to secure the principals' interest. Agency theory, however, has its limits and is criticized due to its model of man as a self-serving utility maximizer while ignoring the complexity of human action and organizational life (e.g., Doucouliagos 1994; Hirsch et al. 1987; Jensen and Meckling 1994).

Stewardship theory responds to the shortcomings of agency theory by studying "situations in which executives as stewards are motivated to act in the best interests of their principals" (Davis et al. 1997, 24; Donaldson and Davis 1991). In contrast to agency theory (Jensen and Meckling 1976), stewardship theory assumes that individuals' behavior is not self-interested but is driven by the interests of the organization. Although there might be a conflict between personal needs and organizational objectives, stewards are assumed to act pro-organizationally because they perceive the utility gained from pro-organizational behavior to be higher than the utility gained from individualistic, self-serving behavior (Davis et al. 1997). In addition to psychological factors, stewardship theory assumes that the steward's performance is influenced by the structural situation in which the behavior is performed. Accordingly, stewardship outcomes are dependent on specific organizational structures (Hernandez 2008), which aligns with findings from volunteer research (Van Schie et al. 2015). Whereas governance and control mechanisms are not adequate to promote stewards' pro-organizational behavior but rather lower their motivation (Argyris 1964), stewardship theory promotes organizational structures that facilitate and empower (Davis et al. 1997).

\section{Stewardship as a Moderator of Motivation- Behavior Relationship}

This article argues that the stewardship perspective helps to understand why some volunteers show more extra-role behavior than others. In addition to the hypothesized direct effect of PSM on extra-role behavior, it assumes that the strength of the motivation-behavior relationship is dependent on the organizational setting and thus formulates alternative hypotheses. According to the management and organization science literature (Barnard 1938; Fleming and Spicer 2014), organizations shape the beliefs and behaviors of their members by a variety of formal and informal mechanisms. This study argues that PSM by itself does relate to extra-role behavior, but its interaction with variables in the organizational culture strengthens individuals' willingness to work extra hours. Accordingly, the relationship between PSM and extra-role behavior depends on a stewardship-oriented organizational culture. If PSMmotivated individuals' perception of the work and organizational context corresponds with the ideas of the stewardship approach, these individuals perform higher levels of extra-role behavior than those working in organizations with no stewardship orientation. A stewardshiporiented culture is thus seen as a promoting work environment.

Instead of testing the effect of a stewardship-oriented culture using a single construct, the multi-faceted nature of stewardship is illustrated by focusing on different aspects of stewardship. Drawing from previous research, we select five features of a stewardship culture that we assume influence individual decisions to work extra hours in fire service. We use two criteria in choosing each determinant: It must reflect the values espoused by stewardship theory, and previous research on volunteering indicates that it supports extra-role behavior. In the following, we develop five hypotheses on the characteristics of a stewardshiporiented culture.

\section{Intrinsic Motivation}

Stewardship theory assumes that individuals are intrinsically motivated to work on behalf of the organization. According to Deci (1972), intrinsically motivated individuals perform tasks for no tangible rewards but the activity itself. In fact, they perform an activity because they find it interesting and enjoyable. Research on volunteering has shown that intrinsic motivation stimulates volunteer work effort (van Schie et al. 2015). Beyond that, individuals volunteer due to personal interest rather than external pressure irrespective of organizational affiliation (Bidee et al. 2013). Despite the comparatively high time demand of volunteer activity, volunteer firefighters, in particular, are characterized as being highly intrinsically motivated (Tõnurist and Surva 2017).

This study assumes that intrinsic motivation strengthens the positive association between PSM and extra-role behavior. This can be explained by referring to research on self-determination: According to Ryan and Connell (1989), prosocial behavior can be understood by the outcomes of identification. Correspondingly, prosocial motivation is characterized by identified regulation when intrinsic motivation is high. Individuals who enjoy their work and value the outcomes of helping others perceive the work as beneficial to their own self-selected goals (Gagné and Deci 2005; Grant 2008). Self-determination thus suggests that individuals with intrinsic motivation feel volition, autonomy, and free choice in their efforts to benefit others and thus perceive prosocial motivation as identified regulation (Ryan and Connell 1989). When intrinsic motivation is high, individuals with prosocial motivation increasingly expend efforts to provide an important outcome goal, such as extra-role behavior, for employees to pursue (Gagné and Deci 2005). In contrast, employees do not enjoy working 
when intrinsic motivation is low but feel pressured when performing extra-role behaviors. In this case, prosocial motivation is characterized as introjected regulation (Ryan and Connell 1989). Self-determination theory assumes that individuals are motivated by the fulfillment of their basic psychological needs for autonomy (Ryan and Deci 2000). If they feel pressured to work extra hours, they may reduce their level of engagement (Bazerman et al. 1998) to regain their sense of autonomy at the expense of organizational performance (Grant 2008).

Grant (2008) tested whether intrinsic motivation moderates the effect of prosocial motivation on the persistence of firefighters and found that those with high levels of both prosocial and intrinsic motivations worked an average of more than 30 overtime hours per week, whereas those with low levels worked approximately 20 overtime hours per week on average. In this study, we hypothesize that intrinsic motivation moderates the relationship between PSM and extra-role behavior.

Hypothesis 2a Intrinsic motivation moderates the relationship between PSM and extra-role behavior.

\section{Job Characteristics}

Stewards' worker motivation is further stimulated by the opportunity for growth and employees' responsibility (Davis et al. 1997). Thus, an influence of job characteristics is assumed. Hackman and Oldham (1976) argue that the attainment of three psychological states (i.e., experienced meaningfulness of work, experienced responsibility for outcomes, and knowledge of actual results) fosters positive personal and work outcomes. Accordingly, jobs must enhance skill variety (i.e., the extent to which an individual must use different skills to perform his or her job), task identity (i.e., the extent to which an individual can complete a whole piece of work), task significance (i.e., the extent to which a job impacts others' lives), autonomy (i.e., the freedom an individual has in performing work), and feedback from the job (i.e., the extent to which a jobs imparts information about an individual's performance) to increase the opportunity for growth and worker responsibility (Hackman and Oldham 1976). These job characteristics consequently increase an individual's work meaningfulness because the individual feels useful and valuable (Humphrey et al. 2007). Research has linked these work characteristics with positive behavioral (e.g., job performance) and attitudinal outcomes (e.g., job satisfaction) (Fried and Ferris 1987). For example, job design is negatively related to turnover intentions from a voluntary organization and positively linked to time spent volunteering (Alfes et al. 2015). Furthermore, well-designed volunteer tasks serve as motivational stimuli for volunteer engagement and organizational citizenship behavior (van Schie et al. 2015).

Similar to the causal mechanisms of the relationship between intrinsic motivation and extra-role behavior, this study hypothesizes that job characteristics moderate the relationship between PSM and extra-role behavior. Individuals with a strong desire to help society might be more willing to work extra hours if they evaluate their job positively in terms of the opportunity for growth and responsibility. PSM is thus expected to have a stronger effect on extra-role behavior when employees perceive a motivating work design.

Hypothesis 2b Job characteristics that correspond with a motivating work design (i.e., autonomy, task significance, task identity, variety, and feedback) moderate the relationship between PSM and extra-role behavior.

\section{Organizational Identification}

Stewardship theory focuses on the psychological linkage between individuals and organizations. Correspondingly, stewards characterize themselves as members of their organization and consider organizational goals and mission as their own (Davis et al. 1997). Organizational identification is defined as "a perceived oneness with an organization and the experience of the organization's successes and failures as one's own" (Mael and Ashforth 1992, 103). Identification makes the organization an extension of the steward's psychological structure and may determine individuals' performance, spontaneous contribution, or related outcomes (Brown 1969; Davis et al. 1997). Identifying individuals (e.g., employees) experience negative comments about the organization personally and claim credit for organizational successes (e.g., Katz and Kahn 1978). They thereby increase their self-image and selfconcept (Kelman 1961; Sussman and Vecchio 1982), which corresponds with the stewardship model (Davis et al. 1997). Individuals who identify with an organization seek to increase organizational success and thus help to solve problems and overcome barriers.

In this study, we assume that organizational identification strengthens the positive association of PSM and extrarole behavior. Individuals who strongly identify with their organizations have positive feelings about their membership and perceive organizational life as their own business (Tajfel and Turner 1979). Research on volunteering (Scott and Stephens 2009; Meisenbach and Kramer 2014; Mayr 2017) and organizational citizenship behavior (van Dick et al. 2006) confirms this notion by indicating that individuals' sense of oneness with an organization fosters their willingness to volunteer and help other members of the organization. Identifying organizational members might 
interpret extra-role behaviors positively and thus may be more willing to engage in extra work, whereby PSM is a channel to expected extra-role behavior. Organizational identification can also stimulate supportive attitudes or even "self-sacrifice" to the organization (Mael and Ashforth 1992; Pratt 1998). Accordingly, individuals who perceive organizational identification such as trust, praise, or regard are more likely to contribute to organizational performance (e.g., Van Dick et al. 2006). Therefore, we hypothesize the following:

Hypothesis 2c Organizational identification moderates the relationship between PSM and extra-role behavior.

\section{Commitment}

Commitment is a characteristic of stewards that makes them believe in and accept organizational goals (Davis et al. 1997; Mayer and Schoorman 1992). Whereas identification reflects psychological oneness, commitment is contingent on social exchange processes and refers to the relationship between separate psychological entities (Van Knippenberg and Sleebos 2006). Meyer and Allen (1991) define commitment as an affective attachment to the organization, a perceived cost associated with leaving the organization, and an obligation to remain in the organization. Individuals with high levels of value commitment align with the organization, share the organization's vision, values, and mission, and are ready to spend time and effort to improve the organization's success (Davis et al. 1997). Similarly, Lee and Olshfski (2002) have shown that firefighters' commitment to the job is linked to extra-role behavior.

This study assumes a moderating effect of commitment on the positive association between PSM and extra-role behavior. Accordingly, it is suggested that a culture of high commitment has a positive effect on the association of PSM and extra-role behavior. Eddleston et al. (2008) found that high levels of commitment to a firm can increase prosocial and pro-organizational helping behavior. Commitment represents a collectivistic motivator (Kollock 1999) and thus is strongly related to work effort and the motivation to contribute additional work in the interest of the collective (Meyer and Allen 1997; Riketta 2002). For example, Mowday et al. $(1982,27)$ state that those who are committed to an organization "are willing to give something of themselves in order to contribute to the organization's well-being." We thus suggest that commitment strengthens the relationship between PSM and extra-role behavior. This leads us to formulate the following hypothesis:

Hypothesis 2d Commitment moderates the relationship between PSM and extra-role behavior.

\section{Perceived Organizational Support}

Stewardship cultures are described as collectivist and with high levels of group cohesion, which is captured by organizational support. Perceived organizational support refers to employees' beliefs concerning the extent to which an organization's management values their contributions and cares about their well-being (Eisenberger et al. 1986; Rhoades et al. 2001). Supportive organizations look after their employees, treat them fairly, and " [go] beyond the call of duty' to benefit a worker" (Randall et al. 1999, 169).

Perceived organizational support is linked to positive organizational outcomes, such as job involvement or positive mood at work (Rhoades and Eisenberger 2002). Furthermore, employees who perceive organizational support are more ready to perform citizenship behavior (Randall et al. 1999; Rhoades and Eisenberger 2002). This phenomenon may be explained by job satisfaction relating to high levels of organizational support (Shore and Tetrick 1991; Cropanzano et al. 1997) or by the norm of reciprocity (Settoon et al. 1996). According to the social exchange perspective (Blau 1964; Cropanzano and Mitchell 2005), individuals respond to a beneficial action by returning a benefit and to a harmful action by returning harm. Consequently, it can be argued that employees who receive support from an organization perform more extra work than those who do not perceive organizational support. Organizational support may be particularly relevant to maintaining and boosting levels of self-esteem and fulfilling the need for social companionship and affiliation (Cohen and Wills 1985). This heightens individual willingness to spend more time in the organization and perform extra work. Research on volunteering confirms these assumptions. Accordingly, volunteers who perceive organizational support are more satisfied, more likely to remain in the volunteer organization (Walker et al. 2016), and spend more effort in accomplishing tasks (Cady et al. 2018). Consequently, we expect organizational support to moderate the relationship between PSM and extra-role behavior and hypothesize the following:

Hypothesis 2e Perceived organizational support moderates the relationship between PSM and extra-role behavior.

\section{Research Setting}

The geographical distribution of fire services in Austria and Germany has its origin in the Prussian system. Given the similar historical roots in both countries, the principle of subsidiarity has characterized the allocation of responsibilities in terms of emergency services and has led to a local structure of fire services in both federal states. Even 
today, fire service is executed at the municipal level in both countries so that each city has at least one fire department (or even several) (Wolter 2011). In Austria, more than 4496 fire departments are located in 2098 municipalities (Austrian Society of Federal Fire Service 2017). In Germany, the number of fire stations also exceeds the number of municipalities: 11,084 municipalities own 22,795 fire departments (German Federal Fire Service 2016). Nearly all of these fire stations are staffed by volunteer firefighters. Only six fire stations in Austria and only 105 in Germany are professional ones. These stations are generally located in large cities with typically more than 100,000 inhabitants and staffed with paid workers (civil servants). Accordingly, 99\% of firefighters in Austria and 94\% of firefighters in Germany are volunteers (Austrian Society of Federal Fire Service 2017; German Federal Fire Service 2016). This is a comparatively high percentage in relation to other European countries (Zeilmayr 2003; Hilgers 2008).

Consequently, volunteer firefighters are essential to ensure safety in Austria and Germany. Their duties are summarized in the principle "save-quench-rescue-protect." In more detail, the core tasks are to save the lives of humans and animals, quench flames, rescue from accidents and protect from dangers such as high watermarks or after heavy thunderstorms. In addition to these core tasks, which are mandated by law, there are many additional activities firefighters can volunteer for. Seven additional activities can be distinguished and described as follows:

(1) Volunteer firefighters train and educate themselves. They organize basic education courses and are responsible for their own transfer of knowledge within the staff and between organizations. (2) Consequently, by organizing basic courses, volunteer firefighters care for the promotion of young fellows and new members. (3) Furthermore, volunteer firefighters are often members of firefighting associations and roundtables to develop, for example, technical or educational standards or emergency plans.

Local volunteer fire services are faced with a high degree of financial autonomy, meaning that in addition to basic funding for housing, vehicles and machinery from public budgets (taxes), additional funding can be obtained for better equipment, training, excursions, and social events that promote fellowship and team cohesion. The latter is an important issue regarding the social structure of the municipal community, where fire services offer group activities and social employment, especially for young people, and contribute by, for example, organizing village festivals. Consequently, volunteer firefighters often work voluntarily as, for example, (4) event managers for their unit or (5) cashiers responsible for accounting, procurement and spending or funding activities or (6) in administrative issues. (7) Finally, volunteer firefighters are often engaged in technical issues of the maintenance of complex machinery (e.g., fire ladder trucks or care for fire prevention issues), such as by giving basic courses for children in schools and kindergartens. ${ }^{1}$ In other countries or in professional fire stations with paid staff in Germany and Austria, some of these duties are performed by administrative staff, outsourced to private companies or performed by non-firefighter-related staff (e.g., maintenance of machinery or education). In the Prusso-German administrative system, however, these activities are assigned to the firefighting realm and performed by volunteer firefighters.

By referring to the literature (Katz 1964; Van Dyne and LePine 1998; Somech and Drach-Zahavy 2000; Turnipseed and Rassuli 2005), this study defines extra-role behavior as those behaviors performed by individuals that go beyond specified role requirements and directly or indirectly benefit organizational goals and society, whereas in-role behavior is characterized as tasks in accordance with formally described roles. In accordance with the theoretical framework, in-role behavior performed by volunteer firefighters in Austria and Germany encompasses the core tasks that are mandated by law. In contrast, extra-role behavior comprises the seven additional activities outlined above, as these activities are voluntary, not part of the role description or formally required, and not formally rewarded or penalized if they are not performed. Besides, these extra activities help to maintain organizational survival and enhance organizational effectiveness.

Consequently our study uses the extra-role behavior of volunteer firefighters as a dependent variable. To operationalize extra-role behavior, we conducted interviews with an expert panel on volunteer fire services and performed a document analysis of regulations and instructions for Austrian and German volunteer fire departments. In these interviews, we obtained detailed insight that the activities mentioned in (1)-(7) are characterized as occasional activities, performed by dedicated and enthusiastic but single members of the organization or fire brigade unit, establishing an informal and often a spontaneous "extra role."

Although employees' extra-role behavior is valuable to all organizations, it seems particularly important to voluntary organizations in emergency service, such as volunteer fire departments, for the following reasons. First, the amount of emergency inserts for volunteer firefighters has increased in the last decades. This is especially the case for very intense inserts because the sheer number of natural disasters, such as high floods or severe thunderstorms, has

\footnotetext{
${ }^{1}$ Several of these additional activities can be related to the extra-role behavior of other professions. For example, Somech and DrachZahavy (2000) and Belogolovsky and Somech (2010) relate the extrarole behavior of teachers, among others, to the organization of social activities for school, volunteering for school committees, and active participation in teachers' meetings.
} 
increased, and the need of modern society to require or ask for help in such events has risen. Second, the range of emergency scenarios has increased because, at least in Austria and Germany, fire brigades are increasingly included in new emergency deployments concerning, for example, environmental protection, the environmental measurement of air quality (e.g., when a fire burns), or chemical assistance at accidents in industrial companies. Third, people increasingly migrate into cities and consequently quit membership in rescue services in rural areas, which is a severe problem for the remaining volunteers. Fourth, demands are continuously increasing in professional life so that individuals have less time for volunteering in fire services. Resource scarcity and a decline in membership, on the one hand, and work-intensive duties, on the other hand, challenge volunteer fire departments to sustain service quality. Consequently, these organizations are likely to feel the need for valuable extra hours for organizational survival on a large scale and must ensure extra work from their volunteers.

Against the backdrop of volunteer firefighters' tremendous social and economic value to society (McLennan et al. 2009), the literature has focused on volunteer firefighters' specific organizational culture, attitudes, motivation, and behavior. By choosing an in-depth ethnographic research design, Desmond (2006) sheds light on the practical logic of firefighting rather than the "cold logic" of rationality. That study focuses on the individual firefighter, his or her feelings when facing a fire, and organizational socialization. More specifically, it describes how individuals transform into the specific habitus of firefighters as embodied by the organization. Firefighters are described as committed to their job and taking their role in the community seriously (Lee and Olshfski 2002). This commitment to the job also becomes evident in their readiness to perform extraordinary efforts. In addition, firefighters' work engagement is explained by high levels of both prosocial and intrinsic motivation (Grant 2008). Drawing on Kahn's concept of engagement (1990), Rich et al. (2010) show that firefighters expend enormous energy in completing tasks beyond fighting fires. They attribute this engagement to individual characteristics and organizational factors. To cope with highly demanding and stressful firefighting tasks (McLennan et al. 2009), social support from family and friends is found to be particularly important for volunteer firefighters (Huynh et al. 2013). Our study contributes to previous research on firefighting by explaining different extents of extra-role behavior of volunteer firefighters in Austria and Germany.

\section{Data and Methods}

\section{Sample and Data Collection}

This study applies quantitative data analysis and follows a dyadic data approach by drawing on two data sources. First, we conduct a survey among volunteer firefighters in Austria and Germany to obtain information on their motivations, attitudes, and behaviors. Second, we use data from an online platform for hydrant reporting to measure firefighters' engagement in equipment management (i.e., the number of hydrants reported in the platform).

To test our hypotheses, we needed access to a large number of volunteer firefighters. Unfortunately, there is no publicly accessible register of volunteers, and social media does not provide access to a sufficiently high number of volunteer fire departments. Consequently, we employed an explorative search strategy to identify Austrian and German volunteer firefighters. We contacted the developer of an online platform for reporting the location of hydrants. The platform provides an online tool for printing plans of the locations of hydrants. These plans of hydrants summarize important facts about a hydrant (e.g., amount of water, pressure, maintenance interval, GPS data and pictures) and can, for example, be used for fire-fighting operations. Because fire departments lack a comprehensive overview of the location of hydrants in their area, firefighters are the primary users of the tool. They developed a map of hydrants by entering all relevant information in the platform.

At the time of data analysis, 6734 individuals in Germany, Austria, Switzerland, and Italy were using the platform to prepare plans for hydrants. The contact addresses obtained from the platform provided access to individuals from several countries and allowed us to study different extents of extra-role behavior. We sent a mailed invitation to participate in a survey on firefighting to all registered users. Before the questionnaire was sent, it was pilot tested and revised accordingly. Unfortunately, 203 pieces of mail were undeliverable. Two reminders were sent, yielding 548 complete questionnaires and a response rate of $8.4 \% .^{2}$

This study focuses on firefighters working in a volunteer fire department (96.51\% of respondents) situated in Austria and Germany (98.67\% of respondents). After excluding those firefighters who received pay for their work at the fire service and those working in countries other than Austria

\footnotetext{
2 The response rate is explained by following reasons. First, 2733 of the 6734 individuals had registered as a user but had never used the service. Second, 1665 users had neither reported a hydrant nor logged in after December 2015. Third, users might not have been interested in participating in a survey on firefighting due to time constraints or a lack of membership in fire service.
} 
and Germany, the sample consisted of 519 firefighters. A total of $58.77 \%$ of the sample respondents were Austrians, and $41.23 \%$ were from Germany. Due to missing data, the final sample size for the regression analysis was 475 . To our knowledge, this is the greatest sample of volunteer firefighters in this context studied to date. ${ }^{3}$

\section{Measures}

\section{Dependent Variable}

The scale for extra-role behavior reflected volunteers' statements regarding how often they engage in activities of training, the promotion of young fellows, advocacy, event management, financial management, administration, and equipment management. As outlined in the previous section, these activities captured tasks that are not part of the role description of a volunteer firefighter. Extra-role behavior was measured by asking survey participants to what extent they engaged in these seven activities. The first six items were measured on a 5-point scale from " 1 " indicating "never" to " 5 " indicating "always". Equipment management was measured by the number of hydrants reported by the online platform.

\section{Independent and Moderating Variables}

The independent, moderating, and control variables were measured by survey data. Unless otherwise indicated, all items used 7-point Likert-type scales with anchors of 1 (disagree strongly) to 7 (agree strongly). If the measures included multiple items, the item scores were averaged. A full list of variables and measurements can be found in "Appendix".

Public service motivation was measured using a short version of Perry's (1996) PSM scale. German items were drawn from Hammerschmid et al. (2009). To measure intrinsic motivation, survey participants were asked, "Why are you motivated to engage in the fire service?"

\footnotetext{
3 The study's sample was compared to samples investigated to date. Mayr (2017) studied 213 volunteer firefighters working in the city of Hamburg, whereas this sample encompasses volunteer firefighters from different German federal states. Prati et al. (2013) also recruited firefighters via the Internet, but utilized recruitment via online advertisements combined with social media and contacted major professional Fire Brigades in Germany and Italy by hand. They ended up with 701 and 623 firefighters, respectively, participating in the study. Hahm et al. (2016) analyzed 2699 firefighters providing emergency services at the scenes of fires, natural disasters and terrorist attacks from eight European countries during a large field study funded by the European Commission. Strauß et al. (2016) investigated a sample of 97 full-time firefighters from the Fire Departments of cities in the Westphalia area of Germany, who were recruited via advertisements on workplace noticeboards and social media.
}

Motivation items were drawn from Gagné et al. (2015) and adapted to the context of fire service. Job characteristics were measured by a 5-item scale adapted from Hackman and Oldham (1974). The item on skill variety was excluded from the scale on job characteristics because the factor loading was below .5. Organizational identification was measured by six items adapted from Mael and Ashforth (1992), using fire departments instead of schools. Items to measure commitment were adapted from Meyer et al. (1993), resulting in a 6-item scale after the factor loadings were checked. Perceived organizational support was measured by an adapted multi-item scale developed by Eisenberger et al. (1997).

\section{Control Variables}

Based on a review of the literature, we identified six variables that could covary with our independent and dependent variables and thus could be controlled for in our analysis. The variable country controlled for cultural differences between Austria and Germany by taking Austria as a reference. To control for the education of the respondents, we asked for the highest level of completed education ( 1 = compulsory school (low education level); $2=$ secondary school (intermediate); 3 = university degree (high)). The study controlled for the respondents' physical ability by taking respondents' age as a proxy, measured by the year of birth (categorical, young $=1986-2000$; intermediate $=1971-1985 ;$ old $=1920-1970)$. Tenure was measured by the duration of membership as a firefighter (categorical, 10 years and less $=1,11-20$ years $=2$, 21-30 years $=3, \quad 31-40$ years $=4, \quad 41-50$ years $=5$ ). Respondents' workload or time restrictions were measured by the number of operations (more than 30 operations per year $=1$ ). Satisfaction with supervision controlled for firefighters' satisfaction with their supervisor and was measured by the subscale on supervision of the Job Descriptive Index developed by Smith et al. (1969).

\section{Results and Discussion}

Table 1 presents an overview of the sample's descriptives. A total of $99.61 \%$ of respondents were male, approximately $50 \%$ were aged between 31 and 45, and approximately $57 \%$ were low educated. Approximately $15 \%$ of respondents had worked as a volunteer firefighter for 10 years or less. The majority of respondents (approximately 38\%) had been serving for between 11 and 20 years.

Table 2 reports the scale means, standard deviations, and correlation coefficients along with the Cronbach's alpha. The multi-item measures report alpha coefficients 
Table 1 Sample descriptives

\begin{tabular}{|c|c|c|c|}
\hline Variable & $N$ & $\%$ & Mean (SD) \\
\hline Gender & 519 & & $.004(.06)$ \\
\hline Male & 517 & 99.61 & \\
\hline Female & 2 & .39 & \\
\hline Education & 511 & & $1.61(.77)$ \\
\hline Low & 292 & 57.14 & \\
\hline Intermediate & 127 & 24.85 & \\
\hline High & 92 & 18 & \\
\hline Age & 519 & & $1.94(.71)$ \\
\hline Young & 148 & 28.52 & \\
\hline Intermediate & 256 & 49.33 & \\
\hline Old & 115 & 22.16 & \\
\hline Country & 519 & & $.41(.49)$ \\
\hline Austria & 305 & 58.77 & \\
\hline Germany & 214 & 41.23 & \\
\hline Number of operations & 516 & & $.49(.5)$ \\
\hline 30 and less & 264 & 51.16 & \\
\hline 31 and more & 252 & 48.84 & \\
\hline Tenure & 519 & & $2.50(.97)$ \\
\hline 10 years and less & 78 & 15.03 & \\
\hline $11-20$ years & 196 & 37.76 & \\
\hline $21-30$ years & 168 & 32.37 & \\
\hline $31-40$ years & 64 & 12.33 & \\
\hline $41-50$ years & 13 & 2.50 & \\
\hline Satisfaction with supervision & 517 & & $5.85(1.17)$ \\
\hline
\end{tabular}

ranging between .62 and .88 . The correlations among the variables were in the predicted directions and consistent with theoretical expectations. These correlations were moderate, with few intercorrelations approaching or exceeding .40.

To test the research model, moderated regression analysis was conducted. Continuous predictor variables were mean-centered to reduce the occurrence of multicollinearity in the moderating analysis, and product terms were calculated to test the moderating effects. To account for any possible issues with multicollinearity in the data, the variance inflation factor (VIF) was assessed to verify the validity and reliability of our empirical approach. Multicollinearity tests dismissed the potential for problems because the mean variance inflation factor did not exceed 1.51 , which is below the typical cutoff of 10 (see Table 3 ).

Table 3 summarizes the results of the regression analysis. The model is statistically significant, and the independent variables, interaction terms, and controls explain $18.45 \%$ of the variation in the dependent variable. Regarding the control variables, the findings indicate no significant effect of citizenship, socio-demographic characteristics, time constraints, or satisfaction with supervision on extra-role behavior. However, tenure is significantly associated with extra-role behavior. This means that individuals with more years spent as firefighters show a higher level of extra-role behavior than their colleagues with lower tenure.

This finding may be explained by individuals' internalization of additional tasks and duties. Job tenure may lead to different perceptions of what employees define as in-role and extra-role behavior (Morrison 1994). Firefighters who have worked for several years may feel an obligation to perform extra work due to higher levels of trust and organizational commitment. Furthermore, tenure is related to gaining experience. Thus, firefighters become more knowledgeable over time and cognitively relate more tasks to their individual activities.

Our first hypothesis examines the direct effect of PSM on extra-role behavior. The findings support this hypothesis by indicating a significant, positive influence of PSM at the $10 \%$ significance level. Firefighters with high levels of PSM perform higher levels of extra-role behavior. This result also supports previous studies testing the effect of PSM on citizenship behavior (Pandey et al. 2008) and prosocial behavior (Esteve et al. 2016). Accordingly, PSM seems to be advantageous for the organization because employees with altruistic beliefs spend more time performing extra work. However, the result has to be interpreted with caution due to the low significance level.
Table 2 Means, standard deviations, and correlations (Cronbach's alphas in parentheses)

\begin{tabular}{llllllllllll}
\hline & Variables & Mean & SD & 1 & 2 & 3 & 4 & 5 & 6 & 7 \\
\hline 1 & Extra-role behavior & 3.37 & .64 & $.64)$ & & & & & & \\
2 & Public service motivation & 5.99 & .77 & $.20^{*}$ & $(.62)$ & & & & & \\
3 & Intrinsic motivation & 6.55 & .59 & $.14^{*}$ & $.34^{*}$ & $(.85)$ & & & & \\
4 & Job characteristics & 5.63 & .94 & $.31^{*}$ & $.32^{*}$ & $.37^{*}$ & $(.78)$ & & & \\
5 & Organizational identification & 5.27 & .86 & $.19^{*}$ & $.33^{*}$ & $.22^{*}$ & $.34^{*}$ & $(.69)$ & & \\
6 & Commitment & 5.62 & .96 & $.29^{*}$ & $.42^{*}$ & $.37^{*}$ & $.40^{*}$ & $.53^{*}$ & $(.77)$ & \\
7 & Perceived organizational & 5.57 & .88 & $.31^{*}$ & $.23^{*}$ & $.33^{*}$ & $.48^{*}$ & $.27^{*}$ & $.34 *$ & $(.86)$ \\
& support & & & & & & & & & \\
\hline
\end{tabular}

The significance levels are indicated as follows: $* p<0.05$ 
Table 3 Regression for extra-role behavior

\begin{tabular}{|c|c|c|}
\hline & \multicolumn{2}{|c|}{ Extra-role behavior } \\
\hline & Coeff. & SE \\
\hline \multicolumn{3}{|l|}{ Predictors } \\
\hline Public service motivation (PSM) & $.07^{+}$ & .04 \\
\hline Intrinsic motivation (INT) & -.05 & .06 \\
\hline Job characteristics (JOB) & $.12 * * *$ & .03 \\
\hline Organizational identification (IDENT) & -.01 & .04 \\
\hline Commitment (COM) & $.08^{*}$ & .04 \\
\hline Perceived organizational support (POS) & $.15^{* * *}$ & .04 \\
\hline \multicolumn{3}{|l|}{ Interaction } \\
\hline $\mathrm{PSM} * \mathrm{INT}$ & -.08 & .07 \\
\hline $\mathrm{PSM} * \mathrm{JOB}$ & .05 & .04 \\
\hline PSM * IDENT & -.05 & .05 \\
\hline $\mathrm{PSM} * \mathrm{COM}$ & $.09 *$ & .05 \\
\hline $\mathrm{PSM} * \mathrm{POS}$ & -.07 & .04 \\
\hline \multicolumn{3}{|l|}{ Control variables } \\
\hline Country (ref. Austria) & -.09 & .06 \\
\hline \multicolumn{3}{|l|}{ Education (ref. intermediate) } \\
\hline Low & -.04 & .07 \\
\hline High & -.04 & .08 \\
\hline \multicolumn{3}{|l|}{ Age (ref. intermediate) } \\
\hline Young & -.07 & .07 \\
\hline Old & .01 & .08 \\
\hline Tenure & $.08^{*}$ & .04 \\
\hline Number of operations & -.05 & .05 \\
\hline Satisfaction with supervision & -.01 & .03 \\
\hline Constant & $3.37 * * *$ & .20 \\
\hline$R^{2}$ & .2172 & \\
\hline Adjusted $R^{2}$ & .1845 & \\
\hline$F$ & $6.65^{* * *}$ & \\
\hline Mean VIF & 1.51 & \\
\hline
\end{tabular}

Linear regression; $N=475$; the significance levels are indicated as follows: ${ }^{+} p<0.10 ;{ }^{*} p<0.05 ;{ }^{* *} p<0.01 ; * * * p<0.001$

With regard to interaction terms, the findings indicate a positive effect of $\mathrm{PSM}^{*} \mathrm{COM}$ on extra-role behavior. Consequently, the findings support Hypothesis $2 \mathrm{~d}$ on the moderating effect of commitment. Individuals with high PSM show a higher level of extra-role behavior if they are committed to the organization and their tasks. This result indicates that individuals who expend extra-role effort are committed not only to the public interest but also to the fire department and their work. Although there is a direct effect of PSM on extra-role behavior, the interaction effect is stronger and more significant. The analysis provides no support for Hypotheses 2a, 2b, 2c, and 2e.

In addition to the moderating effect of stewardship-like factors, several direct effects significantly relate to extra- role behavior. Accordingly, job characteristics have a significant, positive effect on extra-role behavior, a result in line with previous research on volunteering (Alfes et al. 2015; van Schie et al. 2015). Furthermore, commitment positively relates to firefighters' engagement in extra work. Finally, similar to past research (Cady et al. 2018), perceived organizational support has a positive association with extra-role behavior. These results indicate that some aspects of a stewardship-oriented work and organizational context influence individual workers' performance.

Whereas a motivating work design, commitment, and perceived organizational support directly influence the level of extra-role behavior of volunteer firefighters, organizational identification and intrinsic motivation do not predict extra-role performance. The latter finding contradicts the results from Grant (2008), which showed that intrinsic motivation strengthens the relationship between prosocial motivation and performance. In this study, intrinsic motivation is not directly related to extra-role behavior, and the joint effect with PSM is not significant. Although other studies have shown that intrinsic motivation predicts volunteer behavior, it may not provide an explanation for behavior that exceeds role prescriptions (see Schaubroeck and Ganster 1991). The insignificant results might be explained by the variety and complexity of the work (Grant 2008). Previous research has shown that completing varied and complex tasks stimulates intrinsic motivation, whereas repetitive tasks that are perceived as simple are less likely to be promoted with intrinsic motivation (Hackman and Oldham 1976; Koestner and Losier 2002).

\section{Conclusion}

\section{Theoretical Implications}

This paper aimed to examine the effect of individual attitudes, motivation, and perceptions of organizational culture on extra-role behavior. Many volunteer firefighters not only engage in emergency services (i.e., responding to calls for help) but also spend their time going above and beyond the call of duty and engaging in extra work that is advantageous to the fire department and, ultimately, for society. These extra-role behaviors are an important form of organizational behavior that affects organizational performance and survival. In this study, we examined how individual inner conviction and the organizational context matter in terms of individual performance. In terms of rescue and firefighting services, social cohesion seems particularly important. This study showed that firefighters perform their duties not only due to concern for serving the public 
interest but also because of attachment to the organization, companionship, and firefighting activities.

While the determinants of volunteer behavior have been well established, our goal was to broaden our understanding of extra-role behavior in the voluntary context. This study thus contributes to research on volunteer behavior by focusing on a very specific but crucial behavior. It adds to the existing literature by investigating behaviors that go beyond role prescriptions and that are inevitable for organizational success and effectiveness. In doing so, we examined both the simultaneous and joint effects of PSM and factors associated with stewardship on individual performance. Overall, our findings suggest that PSM has a positive effect on volunteer extra-role behavior. Furthermore, firefighters' attachment to the organization and fellow relationships can be a source of performance advantage for fire departments. In the following, the contributions of the findings to theory are discussed.

Our finding regarding the positive effect of PSM on individual willingness to work extra hours contributes to the literature on PSM by shedding light on the outcomes of altruistic motivation. Bozeman and $\mathrm{Su}$ (2015) questioned whether and how PSM corresponds to observable behavior, and various other studies have called for research on this issue (Brewer 2008; Ritz 2009). We show that PSM influences individual volunteer behavior in that PSM-motivated volunteers are more willing to perform extra work compared with those who show lower levels of PSM. Although the effect is only significant at a $10 \%$ level and thus should be interpreted with caution, we can conclude that individuals with high PSM tend to perform higher levels of extra-role behavior. This study contributes to research on the effect of PSM on organizational behavior (e.g., Kim 2006; Pandey et al. 2008; Ritz 2009) in the specific context of voluntary emergency service. Few studies have tested whether PSM can explain volunteer behavior (Coursey et al. 2011; Ertas 2014; Leisink et al. 2018). We contribute to these studies by showing that PSM might be linked to behavior that goes above and beyond the call of duty.

In addition to testing whether PSM influences behavior, this study investigated how PSM relates to extra-role work. We predicted and found support for our claim that individual commitment to the occupation and organization influences the relationship between PSM and extra-role behavior. Whereas extra-role behavior can be explained by an individual inner conviction to serve the public interest, individuals seem to spend even more time and effort on extra-role behavior if they are committed to both the public interest and their job and fire department. Consequently, volunteer firefighters who perform high levels of extra-role behavior have a strong desire to foster the well-being of society and are highly committed to their job and fire department.
Finally, our findings regarding the effect of some aspects of a stewardship-like culture on extra-role behavior contribute to research on stewardship theory. We contribute to the stream of literature of qualitative studies that explore stewardship in organizations by quantitatively testing the effect of stewardship on volunteer performance. We provide support for the notion that the extra-role behavior of volunteers can be stimulated by several characteristics of a stewardship culture. In line with our findings, volunteerism seems to be a cultural rather than a managerial issue. Accordingly, extra work cannot be instructed but rather is an issue of self-actualization based on motivating work, emotional attachment to the organization, and group cohesiveness. Firefighters who perceive their tasks as meaningful and valuable are willing to spend more time in the fire department and help to maintain equipment, support organizing events, and take care of financial management. In addition to positive attitudes toward tasks, commitment to the occupation and organization positively influences their willingness to perform extra work. Finally, extra-role behavior is not isolated from social relationships, but rather support from fellowship has a direct effect on the frequency of extra-work engagement.

\section{Limitations and Directions for Future Research}

Given the importance of extra-role behavior for many outcomes, our findings suggest multiple avenues for future studies that consider how organizations can improve the prosocial organizational behavior of their employees. Although we address several limitations of this research, we are convinced of our study's potential to provide an impetus for further research on the antecedents of extrarole behaviors.

First, our study tested hypotheses in the context of Austrian and German voluntary emergency services. In spite of the effort to recruit a great number of volunteer firefighters in both countries in an explorative manner, we cannot ensure the representativeness of the sample with respect to Austrian and German volunteer firefighters due to a lack of statistical data for comparison. In making a first step toward recruiting a great share of volunteers to test our hypotheses, there are several directions for further research supporting the generalizability of our results. We call for further research that attempts to replicate our results in other field settings because the focus on volunteers in fire service with specific demographic characteristics (i.e., predominately male) might raise questions about generalizability with respect to other volunteer services. Furthermore, national regulations influence volunteer management practices. This study focuses on volunteer fire departments in Austria and Germany, and the findings might differ across countries due to differences in national law, culture, 
and community capacity (Haß and Serrano-Velarde 2015; Henderson and Sowa 2018). Studying extra-role behavior through the lens of institutional theory might be a fascinating area for future research.

Second, this study used cross-sectional data to test theoretical assumptions about the effect of PSM on extra-role behavior. However, Perry et al. (2008) argue that volunteering can generate PSM. Replicating this research by taking a longitudinal approach might be an intriguing area for future research and would allow us to comment on the direction of causality.

Third, this study measured the extent to which volunteers engage in extra work. Although the frequency of engagement is a first step to describe the extra-role behavior of volunteers, another important avenue for future research would be to extend the model by including outcome variables to draw conclusions about the consequences of extra-role behavior for organizational success and effectiveness. Accordingly, it could be asked to what extent extra-role behavior performed by volunteers is beneficial for individual employees (e.g., job satisfaction, motivation, individual performance, and team spirit), the organization (e.g., mobilization of new members, organizational survival, and organizational performance), and society at a large (e.g., trust in fire service, sense of security).

Despite the various positive connotations of extra-role behavior (Podsakoff et al. 2009), past research has also focused on the negative side of citizenship behavior. Employees might feel pressured to continuously work extra hours, which can result in stress and work overload (Bolino et al. 2004; Bolino and Turnley 2005; Vigoda-Gadot 2006). Furthermore, employees' task performance has consequences on other employees' feelings of pressure to work more even if they are unable to do so. Consequently, organizationally induced obligations to work extra hours can also be negatively associated with employee well-being (Bolino et al. 2013; Huynh et al. 2013; Deery et al. 2017). In addition to studying factors that stimulate extrarole behavior, we recommend that future research could examine the consequences of helping behavior on individual employees and the power of organizations to request extra-role performance (Fleming and Spicer 2014).

\section{Practical Implications}

This study's findings have important practical implications. First, high levels of PSM seem to have a positive influence on extra-role behavior, though the effect is only significant at the $10 \%$ level. Research recommends various strategies for increasing PSM by integrating public service values into an organization's management systems (Paarlberg et al. 2008). These strategies could be considered by fire departments to improve performance. Second, various aspects of a stewardship culture positively relate to the extra work of volunteers. Individuals who feel that they are part of a supportive work environment and who perceive group cohesiveness reciprocate this behavior to their colleagues and the organization. Although extra-role performance does not seem to be a managerial issue in the voluntary realm, managers of voluntary organizations may draw on these findings and shape volunteer behaviors. Traditional human resources practices might be ill suited to influence employee behavior in the volunteer and nonprofit context because they are based on control systems and economic responses to manage employee behavior. However, concepts of transformational leadership (Paarlberg and Lavigna 2010; Dwyer et al. 2013; Mayr 2017) focus on higher ideals and moral values (Shamir, House, and Arthur 1993; Tracey and Hinkin 1998). Transformational leaders are advised to give meaning to jobs by communicating the importance of their work and relating work activities to organizational aims and employees' values (Paarlberg and Lavigna 2010), empowering employees (Park and Rainey 2008), and acting as a prosocial role model (Shamir et al. 1993).

Acknowledgements Open access funding provided by Johannes Kepler University Linz.

\section{Compliance with Ethical Standards}

Conflict of interest The authors declare that they have no conflict of interest.

Open Access This article is distributed under the terms of the Creative Commons Attribution 4.0 International License (http://crea tivecommons.org/licenses/by/4.0/), which permits unrestricted use, distribution, and reproduction in any medium, provided you give appropriate credit to the original author(s) and the source, provide a link to the Creative Commons license, and indicate if changes were made.

\section{Appendix}

See Table 4. 
Table 4 Variables and measurement

\begin{tabular}{ll}
\hline Variable & Measure \\
\hline DV: Extra-role behavior & Seven items $(\alpha=.64)$. "How often do you engage in activities of (1) training; (2) promotion of \\
& young fellows; (3) advocacy; (4) event management; (5) financial management; (6) \\
& administration; (7) equipment management." \\
& $(1=$ never; $5=$ always; and by the number of hydrants reported in terms of equipment \\
& management)
\end{tabular}

IV: Public service motivation (Perry 1996) Three items $(\alpha=.62)$. (1) "Meaningful public service is important to me"; (2) "To me, patriotism includes seeing to the welfare of others"; (3) "Making a difference in society means more to me than personal achievements."

$(1$ = disagree strongly; 7 agree strongly)

IV: Intrinsic motivation (Gagné et al. 2015) Four items $(\alpha=.85)$. (1) "Because I enjoy the work at the fire service"; (2) "Because the work at the fire service is fun"; (3) "Because the work at the fire service is exciting"; (4) "Because the work at the fire service is interesting."

$(1$ = disagree strongly; 7 = agree strongly $)$

IV: Job characteristics (Hackman and Oldham 1974)

IV: Organizational identification (Mael and Ashforth 1992)

\section{IV: Commitment}

(Meyer et al. 1993)

IV: Perceived organizational support (Eisenberger et al. 1997)

\section{Control: Country}

Control: Education

Control: Age

Control: Tenure

Control: Number of operations

Control: Satisfaction with supervision (Smith et al. 1969)
Four items $(\alpha=.78)$. (1) "The job is arranged so that I can do an entire piece of work from beginning to end"; (2) "The results of my work are likely to significantly affect the lives of other people"; (3) "The job gives me the chance to use my personal initiative or judgment in carrying out the work"; (4) "The work activities themselves provide direct and clear information about the effectiveness of my job performance."

( 1 = disagree strongly; 7 = agree strongly $)$

Six items $(\alpha=.69)$. (1) "When someone criticizes our work, it feels like a personal insult"; (2) "I am very interested in what others think about the fire department"; (3) "When I talk about the fire department, I usually say "we' rather than 'they",; (4) "The fire department's successes are my successes"; (5) "When someone praises the fire department, it feels like a personal compliment"; (6) "If a story in the media criticized the fire department, I would feel embarrassed."

( 1 = disagree strongly; 7 = agree strongly)

Six items $(\alpha=.77)$. (1) "I am proud to work at the fire service"; (2) "I feel a responsibility to continue working as a firefighter"; (3) "I really feel as if the fire department's problems are my own"; (4) "The fire department has a great deal of personal meaning for me"; (5) "I would feel guilty if I left the fire department now"; (6) "I would not leave the fire department right now because I have a sense of obligation to the people in it."

$(1=$ disagree strongly; 7 = agree strongly $)$

Seven items $(\alpha=.86)$. (1) "My fire department cares about my opinion"; (2) "My fire department really cares about my well-being"; (3) "My fire department strongly considers my goals and values"; (4) "Help is available from my organization when I have a problem"; (5) "My fire department would forgive an honest mistake on my part"; (6) "If given the opportunity, my fire department would take advantage of me" (r.c., excluded due to low factor loading); (7) "My fire department shows very little concern for me" (r.c.); (8) "My fire department is willing to help me if I need a special favor."

( 1 = disagree strongly; 7 = agree strongly $)$

Respondent's country of residence ( 1 = Germany; 0 = Austria)

Respondent's self-reported educational attainment ( 1 = compulsory school; 2 = secondary school; 3 = university degree)

Respondent's age measured by year of birth (1 = young (1986-2000); 2 = intermediate (1971-1985); 3 = old (1920-1970)

Respondent's self-reported years as a volunteer firefighter $(1=10$ years and less; $2=11-20$; $3=21-30 ; 4=31-40 ; 5=41-50$ )

Number of operations of respondent's fire department $(1=$ more than 30 operations per year; $0=30$ and less operations per year)

Respondent's self-reported satisfaction with supervisor.

Five items $(\alpha=.91)$. My direct supervisor (1) is supportive; (2) is equitable; (3) is disliked (r.c.); (4) is trustworthy; (5) has favorites (r.c.).

$(1$ = disagree strongly; 7 = agree strongly $)$

$D V$ dependent variable, $I V$ independent variable, r.c. reversed coded 


\section{References}

Alfes, K., Shantz, A., \& Saksida, T. (2015). Committed to whom? Unraveling how relational job design influences volunteers' turnover intentions and time spent volunteering. VOLUNTAS: International Journal of Voluntary and Nonprofit Organizations, 26(6), 2479-2499.

Argyris, C. (1964). Integrating the individual and the organization. New York: Wiley.

Austrian Society of Federal Fire Service. (2017). Statistics. https:// www.bundesfeuerwehrverband.at/service/download/?lang=\&tax= media_category\&term=download. Accessed 24 April 2018.

Barnard, C. (1938). The functions of executive. Cambridge: Harvard University Press.

Bazerman, M. H., Tenbrunsel, A. E., \& Wade-Benzoni, K. (1998). Negotiating with yourself and losing: Making decisions with competing internal preferences. Academy of Management Review, 23(2), 225-241.

Belogolovsky, E., \& Somech, A. (2010). Teachers' organizational citizenship behavior: Examining the boundary between in-role behavior and extra-role behavior from the perspective of teachers, principals and parents. Teaching and Teacher Education, 26(4), 914-923.

Bidee, J., Vantilborgh, T., Pepermans, R., Huybrechts, G., Willems, J., Jegers, M., et al. (2013). Autonomous motivation stimulates volunteers' work effort: A self-determination theory approach to volunteerism. VOLUNTAS: International Journal of Voluntary and Nonprofit Organizations, 24(1), 32-47.

Blau, P. M. (1964). Exchange and power in social life. Piscataway: Transaction Publishers.

Bolino, M. C., Klotz, A. C., Turnley, W. H., \& Harvey, J. (2013). Exploring the dark side of organizational citizenship behavior. Journal of Organizational Behavior, 34(4), 542-559.

Bolino, M. C., \& Turnley, W. H. (2005). The personal costs of citizenship behavior: The relationship between individual initiative and role overload, job stress, and work-family conflict. Journal of Applied Psychology, 90(4), 740.

Bolino, M. C., Turnley, W. H., \& Niehoff, B. P. (2004). The other side of the story: Reexamining prevailing assumptions about organizational citizenship behavior. Human Resource Management Review, 14(2), 229-246.

Borman, W. C., \& Motowidlo, S. M. (1993). Expanding the criterion domain to include elements of contextual performance. In $\mathrm{N}$. Schmitt \& W. C. Borman (Eds.), Personnel selection in organizations (pp. 71-98). San Francisco: Jossey-Bass.

Bozeman, B., \& Su, X. (2015). Public service motivation concepts and theory: A critique. Public Administration Review, 75(5), 700-710.

Brauchli, R., Peeters, M. C., Steenbergen, E. F., Wehner, T., \& Hämmig, O. (2017). The work-home interface: Linking workrelated wellbeing and volunteer work. Journal of Community \& Applied Social Psychology, 27(1), 50-64.

Brewer, G. A. (2008). Employee and organizational performance. In J. L. Perry \& A. Hondeghem (Eds.), Motivation in public management: The call of public service (pp. 136-156). Oxford: University Press.

Brewer, G. A., \& Selden, S. C. (1998). Whistle blowers in the federal civil service: New evidence of the public service ethic. Journal of Public Administration Research and Theory, 8(3), 413-440.

Brown, M. E. (1969). Identification and some conditions of organizational involvement. Administrative Science Quarterly, 14(3), 346-355.

Cady, S. H., Brodke, M., Kim, J. H., \& Shoup, Z. D. (2018). Volunteer motivation: A field study examining why some do more, while others do less. Journal of Community Psychology, 46(3), 281-292.

Campbell, J. W., \& Im, T. (2016). PSM and turnover intention in public organizations: Does change-oriented organizational citizenship behavior play a role? Review of Public Personnel Administration, 36(4), 323-346.

Clerkin, R. M., Paynter, S. R., \& Taylor, J. K. (2009). Public service motivation in undergraduate giving and volunteering decisions. The American Review of Public Administration, 39(6), 675-698.

Cohen, S., \& Wills, T. A. (1985). Stress, social support, and the buffering hypothesis. Psychological Bulletin, 98(2), 310-357.

Coursey, D., Brudney, J. L., Littlepage, L., \& Perry, J. L. (2011). Does public service motivation matter in volunteering domain choices? A test of functional theory. Review of Public Personnel Administration, 31(1), 48-66.

Coursey, D. H., Perry, J. L., Brudney, J. L., \& Littlepage, L. (2008). Psychometric verification of Perry's public service motivation instrument: Results for volunteer exemplars. Review of Public Personnel Administration, 28(1), 79-90.

Cropanzano, R., Howes, J. C., Grandey, A. A., \& Toth, P. (1997). The relationship of organizational politics and support to work behaviors, attitudes, and stress. Journal of Organizational Behavior, 18(2), 159-180.

Cropanzano, R., \& Mitchell, M. S. (2005). Social exchange theory: An interdisciplinary review. Journal of Management, 31(6), 874-900.

Davis, J. H., Schoorman, F. D., \& Donaldson, L. (1997). Toward a stewardship theory of management. Academy of Management Review, 22(1), 20-47.

Deci, E. L. (1972). The effects of contingent and noncontingent rewards and controls on intrinsic motivation. Organizational Behavior and Human Performance, 8(2), 217-229.

Deery, S., Rayton, B., Walsh, J., \& Kinnie, N. (2017). The costs of exhibiting organizational citizenship behavior. Human Resource Management, 56(6), 1039-1049.

Desmond, M. (2006). Becoming a firefighter. Ethnography, 7(4), $387-421$.

Donaldson, L., \& Davis, J. H. (1991). Stewardship theory or agency theory: CEO governance and shareholder returns. Australian Journal of Management, 16(1), 49-64.

Doucouliagos, C. (1994). A note on the evolution of homo economicus. Journal of Economic Issues, 28(3), 877-883.

Dwyer, P. C., Bono, J. E., Snyder, M., Nov, O., \& Berson, Y. (2013). Sources of volunteer motivation: Transformational leadership and personal motives influence volunteer outcomes. Nonprofit Management and Leadership, 24(2), 181-205.

Eddleston, K. A., Kellermanns, F. W., \& Sarathy, R. (2008). Resource configuration in family firms: Linking resources, strategic planning and technological opportunities to performance. Journal of Management Studies, 45(1), 26-50.

Eisenberger, R., Cummings, J., Armeli, S., \& Lynch, P. (1997). Perceived organizational support, discretionary treatment, and job satisfaction. Journal of Applied Psychology, 82(5), 812-820.

Eisenberger, R., Huntington, R., Hutchison, S., \& Sowa, D. (1986). Perceived organizational support. Journal of Applied Psychology, 71(3), 500-507.

Ertas, N. (2014). Public service motivation theory and voluntary organizations: Do government employees volunteer more? Nonprofit and Voluntary Sector Quarterly, 43(2), 254-271.

Esteve, M., Urbig, D., Van Witteloostuijn, A., \& Boyne, G. (2016). Prosocial behavior and public service motivation. Public Administration Review, 76(1), 177-187.

Fleming, P., \& Spicer, A. (2014). Power in management and organization science. The Academy of Management Annals, 8(1), 237-298. 
Frederickson, H. G., \& Hart, D. K. (1985). The public service and the patriotism of benevolence. Public Administration Review, 45(5), 547-553.

Fried, Y., \& Ferris, G. R. (1987). The validity of the job characteristics model: A review and meta-analysis. Personnel Psychology, 40(2), 287-322.

Gagné, M., \& Deci, E. L. (2005). Self-determination theory and work motivation. Journal of Organizational Behavior, 26(4), $331-362$.

Gagné, M., et al. (2015). The Multidimensional Work Motivation Scale: Validation evidence in seven languages and nine countries. European Journal of Work and Organizational Psychology, 24(2), 178-196.

George, J. M., \& Bettenhausen, K. (1990). Understanding prosocial behavior, sales performance, and turnover: A group-level analysis in a service context. Journal of Applied Psychology, 75(6), 698-709.

George, J. M., \& Brief, A. P. (1992). Feeling good-doing good: A conceptual analysis of the mood at work-organizational spontaneity relationship. Psychological Bulletin, 112(2), 310-329.

German Federal Fire Service. (2016). Statistics on fire service. http:// www.feuerwehrverband.de/statistik.html. Accessed 24 April 2018.

Grant, A. M. (2008). Does intrinsic motivation fuel the prosocial fire? Motivational synergy in predicting persistence, performance, and productivity. Journal of Applied Psychology, 93(1), 48-58.

Hackman, J. R., \& Oldham, G. R. (1974). The job diagnostic survey: An instrument for the diagnosis of jobs and the evaluation of job redesign projects. New Haven: Yale University.

Hackman, J. R., \& Oldham, G. R. (1976). Motivation through the design of work: Test of a theory. Organizational Behavior and Human Performance, 16(2), 250-279.

Hahm, S., Knuth, D., Kehl, D., \& Schmidt, S. (2016). The impact of different natures of experience on risk perception regarding firerelated incidents: A comparison of firefighters and emergency survivors using cross-national data. Safety Science, 82, 274-282.

Hammerschmid, G., Meyer, R. E., \& Egger-Peitler, I. (2009). Das Konzept der Public Service Motivation-Status Quo der internationalen Diskussion und erste empirische Evidenzen für den deutschsprachigen Raum. der moderne staat, 2(1), 73-92.

Haß, R., \& Serrano-Velarde, K. (2015). When doing good becomes a state affair: Voluntary service in Germany. VOLUNTAS: International Journal of Voluntary and Nonprofit Organizations, 26(5), 1718-1738.

Henderson, A. C., \& Sowa, J. E. (2018). Retaining critical human capital: Volunteer firefighters in the commonwealth of Pennsylvania. VOLUNTAS: International Journal of Voluntary and Nonprofit Organizations, 29(1), 43-58.

Hernandez, M. (2008). Promoting stewardship behavior in organizations: A leadership model. Journal of Business Ethics, 80(1), 121-128.

Hilgers, D. (2008). Performance Management in Unternehmen und öffentlichen Verwaltungen. Wiesbaden: Gabler.

Hirsch, P., Michaels, S., \& Friedman, R. (1987). Dirty hands versus clean models. Theory and Society, 16(3), 317-336.

Houston, D. J. (2006). "Walking the walk" of public service motivation: Public employees and charitable gifts of time, blood, and money. Journal of Public Administration Research and Theory, 16(1), 67-86.

Humphrey, S. E., Nahrgang, J. D., \& Morgeson, F. P. (2007). Integrating motivational, social, and contextual work design features: A meta-analytic summary and theoretical extension of the work design literature. Journal of Applied Psychology, 92(5), 1332-1356.

Huynh, J. Y., Xanthopoulou, D., \& Winefield, A. H. (2013). Social support moderates the impact of demands on burnout and organizational connectedness: A two-wave study of volunteer firefighters. Journal of Occupational Health Psychology, 18(1), $9-15$.

Jensen, M. C., \& Meckling, W. H. (1976). Theory of the firm: Managerial behavior, agency costs and ownership structure. Journal of Financial Economics, 3(4), 305-360.

Jensen, M. C., \& Meckling, W. H. (1994). The nature of man. Journal of Applied Corporate Finance, 7(2), 4-19.

Kahn, W. A. (1990). Psychological conditions of personal engagement and disengagement at work. Academy of Management Journal, 33(4), 692-724.

Katz, D. (1964). The motivational basis of organizational behavior. Systems Research and Behavioral Science, 9(2), 131-146.

Katz, D., \& Kahn, R. L. (1978). The social psychology of organizations (2nd ed.). New York: Wiley.

Kelman, H. C. (1961). Processes of opinion change. Public Opinion Quarterly, 25(1), 57-78.

Kim, S. (2006). Public service motivation and organizational citizenship behavior in Korea. International Journal of Manpower, 27(8), 722-740.

Kim, S. (2018). Public service motivation, organizational social capital, and knowledge sharing in the Korean Public Sector. Public Performance \& Management Review, 41(1), 130-151.

Kluvers, R., \& Tippett, J. (2011). An exploration of stewardship theory in a Not-for-Profit organisation. Accounting Forum, $35(4), 275-284$

Koestner, R., \& Losier, G. F. (2002). Distinguishing three ways of being highly motivated: A closer look at introjection, identification, and intrinsic motivation. In E. L. Deci \& R. M. Ryan (Eds.), Handbook of self-determination research (pp. 101-121). Rochester, NY: University of Rochester Press.

Kollock, P. (1999). The economies of online cooperation: Gifts, and public goods in cyberspace. In M. A. Smith \& P. Kollock (Eds.), Communities in cyberspace (pp. 220-239). New York: Routledge.

Lee, S. H., \& Olshfski, D. (2002). Employee commitment and firefighters: It's my job. Public Administration Review, 62(s1), $108-114$.

Leisink, P. L., Knies, E., \& van Loon, N. (2018). Does public service motivation matter? A study of participation in various volunteering domains. International Public Management Journal. https://doi.org/10.1080/10967494.2018.1428254.

MacKenzie, S. B., Podsakoff, P. M., \& Ahearne, M. (1998). Some possible antecedents and consequences of in-role and extra-role salesperson performance. The Journal of Marketing, 62(3), 87-98.

Mael, F., \& Ashforth, B. E. (1992). Alumni and their alma mater: A partial test of the reformulated model of organizational identification. Journal of Organizational Behavior, 13(2), 103-123.

Mayer, R. C., \& Schoorman, F. D. (1992). Predicting participation and production outcomes through a two-dimensional model of organizational commitment. Academy of Management Journal, $35(3), 671-684$.

Mayr, M. L. (2017). Transformational leadership and volunteer firefighter engagement. Nonprofit Management and Leadership, $28(2), 259-270$

McLennan, J., Birch, A., Cowlishaw, S., \& Hayes, P. (2009). Maintaining volunteer firefighter numbers: Adding value to the retention coin. Australian Journal of Emergency Management, 24(2), 40-47.

Meisenbach, R. J., \& Kramer, M. W. (2014). Exploring nested identities: Voluntary membership, social category identity, and identification in a community choir. Management Communication Quarterly, 28(2), 187-213. 
Meyer, J. P., \& Allen, N. J. (1991). A three-component conceptualization of organizational commitment. Human Resource Management Review, 1(1), 61-98.

Meyer, J. P., \& Allen, N. J. (1997). Commitment in the workplace: Theory, research, and application. London: Sage Publications.

Meyer, J. P., Allen, N. J., \& Smith, C. A. (1993). Commitment to organizations and occupations: Extension and test of a threecomponent conceptualization. Journal of Applied Psychology, $78(4), 538-551$.

Millette, V., \& Gagné, M. (2008). Designing volunteers' tasks to maximize motivation, satisfaction and performance: The impact of job characteristics on volunteer engagement. Motivation and Emotion, 32(1), 11-22.

Moorman, R. H., Niehoff, B. P., \& Organ, D. W. (1993). Treating employees fairly and organizational citizenship behavior: Sorting the effects of job satisfaction, organizational commitment, and procedural justice. Employee Responsibilities and Rights Journal, 6(3), 209-225.

Morrison, E. W. (1994). Role definitions and organizational citizenship behavior: The importance of the employee's perspective. Academy of Management Journal, 37(6), 1543-1567.

Moulton, S., \& Feeney, M. K. (2011). Public service in the private sector: Private loan originator participation in a public mortgage program. Journal of Public Administration Research and Theory, 21(3), 547-572.

Mowday, R. T., Porter, L. W., \& Steers, R. M. (1982). Employeeorganization linkages: The psychology of commitment, absenteeism, and turnover. Cambridge: Academic Press.

Moynihan, D. P., \& Pandey, S. K. (2007). The role of organizations in fostering public service motivation. Public Administration Review, 67(1), 40-53.

Organ, D. W. (1988). Organizational citizenship behavior: The good soldier syndrome. Lanham: Lexington Books/DC Heath and Com.

Paarlberg, L. E., \& Lavigna, B. (2010). Transformational leadership and public service motivation: Driving individual and organizational performance. Public Administration Review, 70(5), 710-718.

Paarlberg, L. E., Perry, J. L., \& Hondeghem, A. (2008). From theory to practice: Strategies for applying public service motivation. In J. L. Perry \& A. Hondeghem (Eds.), Motivation in public management: The call of public service (pp. 268-293). Oxford: University Press.

Pandey, S. K., Wright, B. E., \& Moynihan, D. P. (2008). Public service motivation and interpersonal citizenship behavior in public organizations: Testing a preliminary model. International Public Management Journal, 11(1), 89-108.

Park, S. M., \& Rainey, H. G. (2008). Leadership and public service motivation in US federal agencies. International Public Management Journal, 11(1), 109-142.

Perry, J. L. (1996). Measuring public service motivation: An assessment of construct reliability and validity. Journal of Public Administration Research and Theory, 6(1), 5-22.

Perry, J. L., Brudney, J. L., Coursey, D., \& Littlepage, L. (2008). What drives morally committed citizens? A study of the antecedents of public service motivation. Public Administration Review, 68(3), 445-458.

Perry, J. L., \& Hondeghem, A. (2008). Motivation in public management: The call of public service. Oxford: Oxford University Press.

Perry, J. L., \& Porter, L. W. (1982). Factors affecting the context for motivation in public organizations. Academy of Management Review, 7(1), 89-98.

Perry, J. L., \& Wise, L. R. (1990). The motivational bases of public service. Public Administration Review, 50(3), 367-373.
Podsakoff, P. M., Ahearne, M., \& MacKenzie, S. B. (1997). Organizational citizenship behavior and the quantity and quality of work group performance. Journal of Applied Psychology, 82(2), 262-269.

Podsakoff, N. P., Whiting, S. W., Podsakoff, P. M., \& Blume, B. D. (2009). Individual-and organizational-level consequences of organizational citizenship behaviors: A meta-analysis. Journal of Applied Psychology, 94(1), 122-141.

Prati, G., Pietrantoni, L., Saccinto, E., Kehl, D., Knuth, D., \& Schmidt, S. (2013). Risk perception of different emergencies in a sample of European firefighters. Work, 45(1), 87-96.

Pratt, M. G. (1998). Central questions in organizational identification. In D. A. Whetten \& P. C. Godfrey (Eds.), Identity in organizations. Building theory through conversations (pp. 171-207). London: Sage Publications.

Rainey, H. G., \& Steinbauer, P. (1999). Galloping elephants: Developing elements of a theory of effective government organizations. Journal of Public Administration Research and Theory, 9(1), 1-32.

Randall, M. L., Cropanzano, R., Bormann, C. A., \& Birjulin, A. (1999). Organizational politics and organizational support as predictors of work attitudes, job performance, and organizational citizenship behavior. Journal of Organizational Behavior, 20(2), 159-174.

Rhoades, L., \& Eisenberger, R. (2002). Perceived organizational support: A review of the literature. Journal of Applied Psychology, 87(4), 698-714.

Rhoades, L., Eisenberger, R., \& Armeli, S. (2001). Affective commitment to the organization: The contribution of perceived organizational support. Journal of Applied Psychology, 86(5), $825-836$.

Rich, B. L., Lepine, J. A., \& Crawford, E. R. (2010). Job engagement: Antecedents and effects on job performance. Academy of Management Journal, 53(3), 617-635.

Riketta, M. (2002). Attitudinal organizational commitment and job performance: A meta-analysis. Journal of Organizational Behavior, 23(3), 257-266.

Ritz, A. (2009). Public service motivation and organizational performance in Swiss federal government. International Review of Administrative Sciences, 75(1), 53-78.

Ritz, A., Brewer, G. A., \& Neumann, O. (2016). Public service motivation: A systematic literature review and outlook. Public Administration Review, 76(3), 414-426.

Ryan, R. M., \& Connell, J. P. (1989). Perceived locus of causality and internalization: Examining reasons for acting in two domains. Journal of Personality and Social Psychology, 57(5), 749-761.

Ryan, R. M., \& Deci, E. L. (2000). Self-determination theory and the facilitation of intrinsic motivation, social development, and wellbeing. American Psychologist, 55(1), 68-78.

Schaubroeck, J., \& Ganster, D. C. (1991). Beyond the call of duty: A field study of extra-role behavior in voluntary organizations. Human Relations, 44(6), 569-582.

Scott, C. R., \& Stephens, K. K. (2009). It depends on who you're talking to...: Predictors and outcomes of situated measures of organizational identification. Western Journal of Communication, 73(4), 370-394.

Settoon, R. P., Bennett, N., \& Liden, R. C. (1996). Social exchange in organizations: Perceived organizational support, leader-member exchange, and employee reciprocity. Journal of Applied Psychology, 81(3), 219.

Shamir, B., House, R. J., \& Arthur, M. B. (1993). The motivational effects of charismatic leadership: A self-concept based theory. Organization Science, 4(4), 577-594.

Shantz, A., Saksida, T., \& Alfes, K. (2014). Dedicating time to volunteering: Values, engagement, and commitment to beneficiaries. Applied Psychology, 63(4), 671-697. 
Shim, D. C., \& Faerman, S. (2017). Government employees' organizational citizenship behavior: The impacts of public service motivation, organizational identification, and subjective OCB norms. International Public Management Journal, 20(4), 531-559.

Shore, L. M., \& Tetrick, L. E. (1991). A construct validity study of the survey of perceived organizational support. Journal of Applied Psychology, 76(5), 637-643.

Smith, P. C., Kendall, L. M., \& Hulin, C. (1969). The measurement of satisfaction in work and behavior. Chicago: Raud McNally.

Somech, A., \& Drach-Zahavy, A. (2000). Understanding extra-role behavior in schools: The relationships between job satisfaction, sense of efficacy, and teachers' extra-role behavior. Teaching and Teacher Education, 16(5), 649-659.

Strauß, M., Foshag, P., Przybylek, B., Horlitz, M., Lucia, A., SanchisGomar, F., \& Leischik, R. (2016). Occupation and metabolic syndrome: is there correlation? A cross sectional study in different work activity occupations of German firefighters and office workers. Diabetology \& Metabolic syndrome, 8(1), 57.

Sussman, M., \& Vecchio, R. P. (1982). A social influence interpretation of worker motivation. Academy of Management Review, $7(2), 177-186$.

Tajfel, H., \& Turner, J. C. (1979). An integrative theory of intergroup conflict. In W. Austrin \& S. Worchel (Eds.), The social psychology of intergroup relations (pp. 33-47). Pacific Grove, CA: Brooks/Cole.

Taylor, J. (2010). Public service motivation, civic attitudes and actions of public, nonprofit and private sector employees. Public Administration, 88(4), 1083-1098.

Tõnurist, P., \& Surva, L. (2017). Is volunteering always voluntary? Between compulsion and coercion in co-production. VOLUNTAS: International Journal of Voluntary and Nonprofit Organizations, 28(1), 223-247.

Tracey, J. B., \& Hinkin, T. R. (1998). Transformational leadership or effective managerial practices? Group and Organization Management, 23(3), 220-236.

Turnipseed, D. L., \& Rassuli, A. (2005). Performance perceptions of organizational citizenship behaviours at work: A bi-level study among managers and employees. British Journal of Management, 16(3), 231-244.

Van Dick, R., Grojean, M. W., Christ, O., \& Wieseke, J. (2006). Identity and the extra mile: Relationships between organizational identification and organizational citizenship behaviour. British Journal of Management, 17(4), 283-301.

Van Dyne, L., \& LePine, J. A. (1998). Helping and voice extra-role behaviors: Evidence of construct and predictive validity. Academy of Management Journal, 41(1), 108-119.

Van Knippenberg, D., \& Sleebos, E. (2006). Organizational identification versus organizational commitment: Self-definition, social exchange, and job attitudes. Journal of Organizational Behavior, 27(5), 571-584.

Van Loon, N. M., Vandenabeele, W., \& Leisink, P. (2017). Clarifying the relationship between public service motivation and in-role and extra-role behaviors: The relative contributions of personjob and person-organization fit. The American Review of Public Administration, 47(6), 699-713.

Van Schie, S., Güntert, S. T., Oostlander, J., \& Wehner, T. (2015). How the organizational context impacts volunteers: A differentiated perspective on self-determined motivation. VOLUNTAS: International Journal of Voluntary and Nonprofit Organizations, 26(4), 1570-1590.

Vigoda-Gadot, E. (2006). Compulsory citizenship behavior: Theorizing some dark sides of the good soldier syndrome in organizations. Journal for the Theory of Social Behaviour, 36(1), 77-93.

Walker, A., Accadia, R., \& Costa, B. M. (2016). Volunteer retention: The importance of organisational support and psychological contract breach. Journal of Community Psychology, 44(8), 1059-1069.

Williams, L. J., \& Anderson, S. E. (1991). Job satisfaction and organizational commitment as predictors of organizational citizenship and in-role behaviors. Journal of Management, 17(3), 601-617.

Wolter, F. (2011). Volunteer fire departments in Austria and Germany. Berlin: VS Verlag für Sozialwissenschaften.

Zeilmayr, A. (2003). Freiwillige Feuerwehren in Europa. In Rönnfeldt, J. (Eds.), Feuerwehr-Handbuch (pp. 43-54). Stuttgart. 